\title{
IDENTIDADE DO HOMEM MODERNO: DIGNIDADE OU DEGENERAÇÃO? UMA INVESTIGAÇÃO ACERCA DO SOFRIMENTO EM CHARLES TAYLOR E NIETZSCHE
}

\author{
IDENTIDAD DEL HOMBRE MODERNO: DIGNIDAD O DEGENERACIÓN? UNA INVESTIGACIÓN \\ ACERCA DEL SUFRIMIENTO EN CHARLES TAYLOR Y NIETZSCHE
}

Francisco Alvarenga Junnior Neto*

\begin{abstract}
RESUMO
A questão que pretende-se norteadora deste texto direciona-se à igualdade metodológica entre o pensamento de Charles Taylor e Nietzsche, bem como suas diferentes compreensões acerca da construção do edifício moral. Daquilo que torna próximas as duas expressões filosóficas, certamente é possível pontuar a leitura histórica a que os dois se propõem realizar. Entretanto, enquanto em Taylor o que se pretende, com certa relevância, principalmente em seu livro As fontes do self, é, por meio de uma hermenêutica genealógica, aclarar as fontes da moral que prefiguram a relação entre identidade e bem na modernidade, em Nietzsche a busca pela origem da moralidade assume uma posição negativa e aponta para a decadência do homem. Diferente de Taylor que viu em tal negação as raízes da dignidade do homem moderno, Nietzsche concebe essa relação como degeneração de tudo que é grande no homem, que só é possível a partir da afirmação não só do belo, mas, também, do feio e do sofrimento, como instantes de possibilidade de um vir-a-ser maior.
\end{abstract}

PALAVRAS-CHAVE: Nietzsche. Sofrimento. Taylor.

\section{RESUMEN}

La cuestión que se pretende orientar de este texto se dirige a la igualdad metodológica entre el pensamiento de Charles Taylor y Nietzsche, así como sus diferentes comprensiones acerca de la construcción del edificio moral. De lo que hace próximas las dos expresiones filosóficas, ciertamente es posible puntuar la lectura histórica a la que los dos se proponen realizar. Sin embargo, mientras que en Taylor lo que se pretende, con cierta relevancia, principalmente en su libro Las fuentes del Self, es, por medio de una hermenéutica genealógica, aclarar las fuentes de la moral que prefigura la relación entre identidad y bien en la modernidade, en Nietzsche la búsqueda por el origen de la moralidad asume una posición negativa y apunta a la decadencia del hombre. A diferencia de Taylor que vio en tal negación las raíces de la dignidad del hombre moderno, Nietzsche concibe esa relación como degeneración de todo lo grande en el hombre, que sólo es posible a partir de la afirmación no sólo de lo bello, sino también del feo y, del sufrimiento, comprendiéndolo como instante de posibilidad de un venir a ser mayor.

PALABRAS CLAVE: Nietzsche. Sufrimiento. Taylor.

\footnotetext{
* Mestrando em Filosofia pela Faculdade Jesuíta de Filosofia e Teologia (FAJE). Licenciado em Filosofia pelo Instituto Santo Tomás de Aquino (ISTA). E-mail: franciscocmf@ gmail.com.
} 


\section{INTRODUÇÃO}

A questão que se pretende norteadora deste texto se direciona à igualdade metodológica entre o pensamento de Charles Taylor e Nietzsche, bem como suas diferentes compreensões acerca da construção do edifício moral moderno. Daquilo que os torna próximos, é possível pontuar a leitura histórica à que os dois se propõem realizar. Entretanto, enquanto em Taylor o que se pretende, com certa relevância, principalmente em seu livro As fontes do self (1997), é, por meio de uma hermenêutica genealógica, aclarar as fontes da moral que prefiguram a relação entre identidade e bem na modernidade, em Nietzsche a busca pela origem da moralidade assume uma posição negativa e aponta para a decadência do homem.

Tanto Taylor quanto Nietzsche grifam alguns fenômenos ou reações do homem como marcas da identidade. Taylor (1997, p. 31) aponta "três eixos daquilo que se pode denominar, no sentido mais amplo, pensamento moral": o respeito, a busca constante de evitar o sofrimento e o espanto diante da injustiça.

No que diz respeito ao diagnóstico da formação do homem moderno, não há diferenças significativas entre o apontado pelo filósofo canadense e pelo alemão. Porém, é a partir do desenrolar avaliativo de cada um que surge uma diferença abismal que os desvincula, colocando cada qual em um polo do pensamento filosófico.

\section{O LUGAR DO SOFRIMENTO NO PENSAMENTO DE NIETZSCHE E TAYLOR}

Dos três eixos apontados por Taylor, em As fontes do self (1997) - o respeito, a busca constante de evitar o sofrimento e o espanto diante da injustiça - que denominam o pensamento moral, um que possui relevância não só no pensamento filosófico, mas, também, na vida de Nietzsche, é o sofrimento. Aqui surge um primeiro distanciamento entre as avaliações dos dois filósofos. Taylor escreve:

Somos bem mais sensíveis ao sofrimento, o que, claro, podemos traduzir em simplesmente não querer ouvir falar dele, em vez de o expressarmos na tomada de alguma ação corretiva concreta. Mas a noção de que temos de reduzir o sofrimento a um mínimo é parte integrante daquilo que o respeito significa para nós hoje - por mais desagradável que isso tenha sido para uma eloquente minoria, em particular para Nietzsche. (TAYLOR, 1997, p. 27). 
Em Taylor (1997, p. 16), o constante ato de evitar o sofrimento, juntamente com outras ações do homem moderno, em comparação com o homem de períodos passados, é o que "torna nossa vida significativa ou satisfatória". Taylor, à sua maneira, compreende que todas as nossas intuições morais estão diretamente ligadas à forma com que nos colocamos diante da vida. O que não é diferente em Nietzsche. Porém, aquilo que pelo primeiro é tomado como dignificador do indivíduo, pelo segundo é visto como um sintoma da decadência humana.

O sofrimento é visto por Nietzsche como possibilidade edificadora de um homem superior, capaz de dizer sempre um sim à vida. Essa intuição nietzschiana está precisamente compreendida em seu apontamento de existência de duas classes de homens, regidas por morais distintas, moral do senhor e moral do escravo:

[...] existem dois tipos de sofredores, os que sofrem de abundância de vida, que querem uma arte dionisíaca e também uma visão e compreensão trágica da vida - e depois os que sofrem de empobrecimento de vida, que buscam silêncio, quietude, mar liso, redenção de si mesmos mediante a arte e o conhecimento, ou a embriaguez, o entorpecimento, a convulsão, a loucura. (NIETZSCHE, 2012, p. 245).

Para Nietzsche, a relação com o sofrimento de forma afirmativa é a base para uma autoafirmação. Ele compreende a natureza como lugar de embate e complementação entre forças que ora se digladiam e ora se completam, Forças ativas e forças reativas. No pensamento do filósofo alemão, a excelência da vida humana está estreitamente ligada à ideia de vontade de potência. Ideia que toma singular importância para o filósofo em sua tarefa de compreender a vida como algo que possui valor em si e se encontra em constante movimento na busca de mais potência:

\footnotetext{
Querendo-vir-a-ser-mais-forte, a força esbarra em outras que a ela resistem; é inevitável a luta - por mais potência. A cada momento, as forças relacionam-se de modo diferente, dispõem-se de outra maneira; a todo instante, a vontade de potência, vencendo resistências, se auto-supera e, nessa superação de si, faz surgir novas formas. Enquanto força eficiente, é, pois, força plástica, criadora. É o que revela a própria expressão Wille zur Macht: o termo Wille entendido enquanto disposição, tendência, impulso e Macht associado ao verbo machen, fazer, produzir, formar, efetuar, criar. A vontade de potência é o impulso de toda força a efetivar-se e, com isso, criar novas configurações em sua relação com as demais (MARTON, 2000. P. $55)$.
}

O anunciador de Zaratustra não viu somente a fuga do sofrimento como via de apequenamento do homem. Sua compreensão filo-fisiológica sobre o sofrimento está para além do ato simplório de querê-lo viver ou negá-lo. Vale ressaltar, que na própria busca pela 
origem ou - utilizando a linguagem de Taylor - fontes da moralidade, Nietzsche consegue vislumbrar algo a mais que o canadense. Com o método genealógico, o filósofo da Basiléia não buscou somente apreender os valores primordiais da identidade do homem moderno, tal qual o fez Taylor em As fontes do Self (1997), mas empreendeu compreender sobre quais aspectos o valor dos valores surgiu e foi engendrado. Em outras palavras: a avaliação nietzschiana busca avaliar o valor dos valores em sua gênese. Ele buscou compreender:

Sob que condições o homem inventou para si os juízos de valor "bom" e "mau"? E que valor têm eles? Obstruíram ou promoveram até agora o crescimento do homem? São indícios de miséria, empobrecimento, degeneração da vida? Ou, ao contrário, revela-se neles a plenitude, a força, a vontade de vida, sua coragem, sua certeza, seu futuro? (NIETZSCHE, 2009, p. 09).

Para Nietzsche a avaliação deve ultrapassar aquilo que se apresenta como algo já dado. Assim, dirá ele que a posição do homem diante do sofrimento não é apequenadora somente no ato de querer negá-lo, mas, também, na forma com que o sofrimento vinha sendo afirmado durante a história da humanidade, sendo esta afirmação um sintoma de degeneração da vida, uma vez que:

\footnotetext{
O homem, o animal mais corajoso e mais habituado ao sofrimento, não nega em si sofrer, ele o deseja, ele procura inclusive, desde que lhe seja mostrado um sentido, um para quê no sofrimento. A falta de sentido do sofrer, não o sofrer, era a maldição que até então se estendia sobre a humanidade - e o ideal ascético lhe ofereceu um sentido! (NIETZSCHE, 2009, p. 149).
}

Assim, compreende o filósofo que há uma classe dos homens que veem no sofrimento a possibilidade de elevação da vida para se alcançar um ideal extramundano. Com a religião o homem passa a dar sentido ao sofrimento, porém, não é o mesmo valor dado pelo filósofo da Basileia. A humanidade, segundo Nietzsche, por meio da arte, da religião e da filosofia metafísica busca modificar o efeito que o sofrimento produz, transformando nossa compreensão sobre os acontecimentos "reinterpretando o infortúnio como um bem, cuja utilidade se torne visível depois" (NIETZSCHE, 2000, p. 85). Ainda, em o Anticristo (1989), Nietzsche aponta que o sofrimento, quando não negado, ao ser afirmado, é compreendido como mercadoria. Idiossincrasia religiosa-moral:

No Cristianismo, nem a moral nem a religião contactam em ponto algum com a realidade. Somente causas imaginárias ("Deus", "alma", "espírito", o "livre" ou também o "não livre-arbítrio"); só efeitos imaginários ("pecado", "salvação", "graça", "castigo", "remissão dos pecados"). Um comércio entre seres imaginários 
("Deus", "espíritos", “almas"); uma ciência natural imaginária ("antropocêntrica"; carência total do conceito de causas naturais); uma psicologia imaginária (só erros sobre si mesmo, interpretações de sentimentos gerais agradáveis ou desagradáveis, por exemplo, dos estados nervus sympathicus, com auxílio da linguagem simbólica da idiossincrasia religioso-moral - ("arrependimento", "remorso", "tentação do demônio", "presença de Deus"); uma teologia imaginária ("o Reino de Deus", o "juízo final”, a "vida eterna"). Este mundo de ficções puras distingue-se, para desvantagem sua, do mundo dos sonhos, o qual reflecte pelo menos a realidade, ao passo que ele falseia, desvaloriza e nega a realidade. Depois de se ter criado o conceito "natureza" como noção oposta a "Deus", "natural" transformou-se necessariamente em sinómio de "desprezível" - todo esse mundo de ficções tem a sua raiz no ódio contra o natural (- a realidade! -), é a expressão de um profundo mal-estar perante o real... Mas assim tudo se explica. Quem tem razões, para através da mentira, se evadir da realidade? Quem por causa dela sofre. Mas sofrer por causa da realidade equivale a ser uma realidade infeliz... A preponderância dos sentimentos de desprezar sobre os sentimentos de prazer é a causa de uma moral e de uma religião fictícias; semelhante predomínio fornece a fórmula para a décadence... (NIETZSCHE, 1989, p. 28).

Há, ainda, uma outra desvinculação entre a compreensão de Taylor e de Nietzsche. Na concepção de Taylor, há na modernidade uma clara valorização da autonomia que se relaciona com a ideia de sofrimento na elucidação moderna acerca do respeito. Sem embargo, por mais que haja uma aproximação entre o pensamento de Taylor e o de Nietzsche acerca da importância do sofrimento para a formação da identidade do homem moderno - lembrando que a importância do tema no pensamento de um é inversa à do outro -, ao que tange à autonomia, louvada por Taylor em seu texto, surge novamente entre os dois um desmedido abismo. Em Nietzsche, esses princípios dominantes da agenda moral do Ocidente moderno nada mais fizeram do que submeter a humanidade a uma dominação, denominada por Nietzsche como moral do rebanho.

Tudo foi distorcido e mentido até o âmago pelos bons. Afortunadamente o mundo não se acha construído sobre os instintos tais que apenas os bondosos animais de rebanho nele achassem sua estreita fortuna; exigir que todos se tornassem "homens bons", animais de rebanho, de olhos azuis, benevolentes, "almas belas" ou, como deseja o sr. Hebert Spencer, altruístas - significaria castrar a humanidade e reduzi-la a uma mísera "chinesaria". - E isto se tentou fazer!... Exatamente isso se chamava moral!... (NIETZSCHE, 1995, p. 112).

Vale, a esta altura, retornarmos à premissa nietzschiana de que o sofrimento é edificador. O que Nietzsche buscou realizar durante seu percurso filosófico foi transmutar o valor da vida. Em seu pensamento, o processo de afirmação da vida assimila o sofrimento como edificante de um estado mais elevado do homem por meio de uma filosofia trágica. É na compreensão, aceitação e afirmação da vida que o homem se constitui como - novamente para nos aproximarmos da linguagem de Taylor - digno. O tema do sofrimento em Nietzsche 
deve ser vislumbrado por meio de um olhar consciente do Amor-Fati e do Eterno retorno, dado que

\begin{abstract}
A lição do eterno retorno é que não há retorno do negativo. O eterno retorno significa que o ser é seleção. Só retorna aquilo que afirma ou aquilo que é afirmado [...] no eterno retorno, o ser se diz do devir, mas o ser do devir se diz só do devirativo. (DELEUZE, 1976, p. 217).
\end{abstract}

Deleuze compreende a doutrina do eterno retorno e percebe que no pensamento nietzschiano o homem se encontra emergido no vir-a-ser da efêmera existência e, com isso, faz-nos compreender o Amor-Fati como uma máxima para a existência possuidora de uma excelência em si mesma:

Amor fati [amor ao destino]: seja este, doravante, o meu amor! Não quero fazer guerra ao que é feio. Não quero acusar os acusadores. Que minha única negação seja desviar o olhar! E, tudo somado e em suma: quero ser, algum dia, apenas alguém que diz Sim. (NIETZSCHE, 2012, p. 166).

Se nos defrontarmos com o tema do sofrimento no pensamento de Nietzsche sem considerarmos suas elucidações sobre o Eterno retorno e o Amor-Fati, possivelmente concordaremos com Taylor ao tomar a fuga do sofrimento presente na humanidade como uma das fontes da identidade do homem moderno de forma afirmativa. Porém, se nos propusermos a percorrer as veredas desbravadas pelo filósofo alemão, compreenderemos que, tal qual Taylor compreende, o tema da fuga do sofrimento é uma das fontes da identidade do homem moderno, porém, de forma negativa.

\title{
CONCLUSÃO
}

Enquanto o filósofo canadense considera a fuga do sofrimento, junto com outros fenômenos, causa de um efeito valoroso que resultou na dignidade da vida humana, para Nietzsche a negação do sofrimento é a negação da própria vida que se organiza na relação de forças. Diferente de Taylor, que viu em tal negação as raízes da dignidade do homem moderno, Nietzsche concebe essa relação como degeneração de tudo que é grande no homem. O que o filósofo da Basileia pretende é a elevação da vida humana a partir da afirmação não só do belo, mas, também, do feio, do sofrimento, compreendendo-o como instante de possibilidade de um vir-a-ser maior. 


\section{REFERÊNCIAS}

DELEUZE, Gilles. Nietzsche e a filosofia. Tradução Ruth Jofilly Dias e Edmundo Fernandes Dias. Rio de Janeiro: Editora Rio, 1976.

MARTON, Scarlet. Nietzsche: das forças cósmicas aos valores humanos. Belo Horizonte: Editora UFMG, 2000.

NIETZSCHE, F. O anticristo: anátema sobre o cristianismo. Tradução Artur Morão. Lisboa: Edições 70, 1989.

NIETZSCHE, F. Ecce homo: como alguém se torna o que é. Tradução Paulo Cézar de Souza. São Paulo: Companhia das Letras, 1995.

NIETZSCHE, F. Humano, demasiado humano: um livro para espíritos livres. Tradução Paulo César de Souza. São Paulo: Companhia das Letras, 2000.

NIETZSCHE, F. Genealogia da moral: uma polêmica. Tradução Paulo César de Souza. São Paulo: Companhia das Letras, 2009.

NIETZSCHE, F. A gaia ciência. Tradução Paulo César de Souza. São Paulo: Companhia das Letras, 2012.

TAYLOR, Charles. As fontes do self: a construção da identidade moderna. Tradução Adail Ubirajara Sobral e Dinah de Abreu Azevedo. São Paulo: Edições Loyola, 1997. 